\title{
Ultrasonic evaluation of the physical and mechanical properties of
}

\section{granites.}

G. Vasconcelos ${ }^{\mathrm{a}}$, P.B. Lourenço ${ }^{\mathrm{a}}$, C.A.S. Alves ${ }^{\mathrm{b}}$, J. Pamplona ${ }^{\mathrm{b}}$

${ }^{a}$ ISISE, University of Minho, Department of Civil Engineering, 4800-058 Guimarães, Portugal

${ }^{\mathrm{b}}$ Research Centre of Geologic, Planning and Resources valorization, Department of Earth Sciences, University of Minho, Braga, Portugal

\begin{abstract}
Masonry is the oldest building material that survived until today, being used all over the world and being present in the most impressive historical structures as an evidence of spirit of enterprise of ancient cultures. Conservation, rehabilitation and strengthening of the built heritage and protection of human lives are clear demands of modern societies. In this process, the use of nondestructive methods has become much common in the process of diagnosis of structural integrity in masonry elements.

With respect to the evaluation of the stone condition, the ultrasonic pulse velocity is a simple and economical tool. Thus, the central issue of the present paper concerns the evaluation of the suitability of the ultrasonic pulse velocity method for describing the mechanical and physical properties of granites and for the assessment of its weathering state. For this purpose, results of measurements of the ultrasonic pulse velocity using distinct natural frequency of the transducers was carried out on specimens with different size and shape. The discussion of the factors that induce variations on the velocity measurements is also provided.
\end{abstract}


Additionally, statistical correlations between ultrasonic pulse velocity and mechanical and physical properties of granites are discussed. The major output of the work is the confirmation that ultrasonic pulse velocity can be effectively used as a simple and economical nondestructive method for a preliminary prediction of mechanical and physical properties, as well as a tool for the assessment of the weathering changes of granites that occur during the serviceable life. This is of much interest due to the usual difficulties in removing specimens for mechanical characterization.

Keywords: granite, non-destructive testing, ultrasonic pulse velocity, testing, moisture , weathering, planar anisotropy 


\section{Introduction}

One of the major challenges in rehabilitation and repair of existing structures is inspection, which includes the detection of damaged zones, cracks and defects, and mechanical characterization of materials. This task is generally carried out not only based on experimental investigation on the laboratory but also by means of in situ nondestructive testing. Sophisticated non destructive techniques have been developed and improved throughout the years and are applied to various types of structures in distinct fields, namely masonry structures. One example of such techniques is the ground probe radar, which appears to be a powerful tool in the detection of voids and structural irregularities such as inclusions, moisture content and in the identification of the cross section of ancient multiple leaf masonry walls [1,2]. Another example is given by sonic tests, which allow e.g. the evaluation of the morphology of the masonry walls, detection of voids or crack damage patterns [3]. In both cases, by using appropriate tomography techniques, it is possible to reconstruct the internal characteristics of structural element. These tests are mainly used in structural identification, whereas other type of tests is normally used for material characterization. An example of such a technique is given by the controlled micro-drilling, which can be correlated with the elastic and strength properties of brick [4]. The ultrasonic pulse velocity method falls in last this category as a expedite and economical nondestructive technique.

Ultrasonic pulse velocity (UPV) testing is reported by several authors $[5,6]$ as a useful and reliable non destructive tool of assessing the mechanical characteristics of concrete from existing structures, such as, the modulus of elasticity and the compressive strength. These parameters can be subsequently used in the safety evaluation of the structure. In the field of timber structures, the results are far less appealing due to the anisotropy and 
variability of mechanical properties $[7,8]$. But in the field of rock structures, the ultrasonic pulse velocity has also been suggested as a useful method for an estimation of elastic and strength properties. This aim has been accomplished by means of empirical correlations between the ultrasonic pulse velocity and the compressive strength and modulus of elasticity [9-11].

UPV can be also of use to evaluate closed cracks in a material [12] or to study concrete behavior at early stage, namely in the analysis of the concrete microstructure development [13-16]. When associated to tomography, UPV can give good qualitative information on the changes on material properties as well as on its microcracking state [17-19]. Kahraman [20] also studied the influence of the fracture roughness of granites on UPV and provided a correlation between both parameters. Although acoustic emission seems more appropriate in the evaluation of the crack damage in concrete and especially in rocks under uniaxial compression [21-23], UPV seems also to provide some indication about the damage in concrete [24].

The main goal of the present study is to provide correlations for a wide variety of granites between UPV and mechanical properties in tension and compression, as well as and physical properties (porosity and density). A discussion about the factors that influence variations on the velocity measurements is also carried out, namely with respect to moisture content, weathering state and material anisotropy.

The relevance of the proposed statistical correlations is the possibility of estimating the mechanical properties of granitic lithotypes from ancient masonry structures, which are very common in the Northern region of Portugal and several other countries. This is of relevance in diagnosis and inspection of the structural and material condition, reducing 
the need of sampling material cores and making stone conservation treatments more cost-efficient.

\section{Brief description of the material}

Granite is the most used stone in the construction of ancient buildings, ornamental elements and movable stone heritage artifacts (e.g. statues, altar pieces, benches, etc.) in the North of Portugal, either in monumental or vernacular architecture. A wide range of granitic rocks is present in masonry buildings and artifacts, depending on their petrographic features, such as grain size and internal texture. Therefore, the mechanical characterization of only one type of granite would be rather limitative. In addition, the weathering processes, to which granites are subjected through years, lead to changes on the mechanical properties that require characterization.

The granitic types considered in the present study were mostly collected from the Northern region of Portugal. The selection of the granite types was based on mineralogical, textural and structural characteristics. Thus, fine to medium, medium to coarse, and coarse-grained granites were selected (some with porphyritic textures). In addition to these criteria, the presence of planar anisotropies and the weathering condition were also considered. With respect to planar anisotropies, it is noted that: (a) the natural orientation planes of granitic rocks or preferred orientation of minerals (foliation) can be relevant for further analysis of the variation of the mechanical properties [25]; (b) three orthogonal planes can be identified as rock splitting planes (quarry planes), defined as planes of preferred rupture. The rift plane is the plane corresponding to the easiest splitting in the quarry being easily recognized by the quarryman. 
In the granites tested, the foliation was marked, when macroscopically discernible, and the orientation of the quarry rift planes was marked with the help of the quarryman. A brief description of the different types studied here is given in Table 1. The more weathered types of the same granite facies are designated with an asterisk (*).

Additionally, the loading directions considered for each granite type are also indicated. It should be noted that the fresh granite PTA exhibits a clear preferential planar orientation but this feature was not visible, macroscopically, on the weathered type PTA*.

\section{Experimental testing}

\subsection{Mechanical and physical characterization}

The mechanical characterization of granites aimed at obtaining the complete behavior of different types of granite under tensile and compressive loading, thus, achieving an overview of relevant engineering properties, namely elastic, strength and fracture properties. Obtaining the softening behavior of rock materials is only possible by performing tests under closed-loop control. For the direct tensile tests, a CS7400S servo-controlled universal testing machine with fixed end platens was used. This equipment has a load cell connected to the vertical actuator with a capacity of $22 \mathrm{kN}$, being particularly suitable for small specimens. Due to the limited distance between platens, prismatic specimens of $80 \mathrm{~mm}$ height, $50 \mathrm{~mm}$ length and $40 \mathrm{~mm}$ width were adopted, see Fig. 1a. Such dimensions are less favorable in case of coarse-grained granites and granites with porphyritic texture, since larger representative material volume would be ideally required [26]. To overcome this limitation, a larger number of specimens were tested, so that the effect of the scatter in the results is reduced and the 
average values are representative of the macroscopic properties, especially in the case of coarser granites (PLA and PLA*). Two lateral notches with a depth of $5 \mathrm{~mm}$ at mid height of the specimen were introduced by means of a diamond sawing machine in order to localize the fracture path. The specimens were fixed to the steel platens through the application of an epoxy resin. Due to the brittle behavior of granite, direct tensile tests had to be conducted using very low values of velocity, which varied between $0.08 \mu \mathrm{m} / \mathrm{s}$ and $0.5 \mu \mathrm{m} / \mathrm{s}$. More details about the direct tensile testing can be found in [27]. The specimens to be tested under uniaxial compression were prepared in accordance with ASTM D2938-95 (2002) standard [28]. A diameter of 75mm was adopted for all specimens and the length to diameter ratio was slightly higher than 2.0. Such dimensions are sufficient to be in agreement with the standard but, for coarse-grained granites that exhibit porphyritic internal texture, the diameter is smaller than 10 times the largest grain. In the preparation of the specimens, special care was taken to ensure parallel ends and perpendicular to the longitudinal axis. In addition, the specimen ends were suitably ground so that a smooth surface could be obtained. The uniaxial compressive tests were carried out in a very stiff frame connected with an appropriate closed-loop control system. Some of the granites to be tested were expected to have very high compressive strength and the internal variable selected as feedback signal was the lateral deformation, measured by a tailored made device [29]. In order to reduce the friction coefficient between specimens and steel platens, two oiled sheets of Teflon with a thickness of $100 \mu \mathrm{m}$ were placed at the interfaces between the specimen and the steel platens, see Fig. $1 \mathrm{~b}$.

The knowledge of the physical properties of rocks like porosity and density allows a better understanding of the variations on the mechanical properties. The physical 
properties of the granites were determined in accordance with [26]. In order to use representative samples of rock masses and taking into account the average dimension of the grains, cubic specimens of approximately $150 \times 150 \times 150 \mathrm{~mm}^{3}$ were used in the porosity test. Porosity tests were repeated in all specimens tested under tensile and compressive loading.

\subsection{Nondestructive testing}

As mentioned above, the main goal of using UPV testing as a non destructive technique is the correlation with elastic and strength properties of the granites under study. This implies that measurements of these mechanical properties and the NDTs should be made on the same specimens. Thus, before tensile and compressive tests have been undertaken, the ultrasonic pulse velocity was measured in each specimen. According to ASTM D2845-05 (2005) [30], the ultrasonic pulse velocity is influenced by the shape and size of the specimens. Therefore, ultrasonic pulse velocity measurements were also made in cubic specimens used in the porosity tests. Below, a comparison of the results obtained in the specimens with distinct shape and size are performed. Finally, since moisture content of the tests specimen is expected to affect the ultrasonic pulse velocity, two extreme moisture conditions were considered: dry and saturated.

The ultrasonic pulse measurements were carried out by using the TICO equipment from Proceq. Piezoelectric transducers of natural resonance frequency of $54 \mathrm{kHz}$ and $150 \mathrm{kHz}$ were used in the measurements. The main reason for using distinct frequencies was the small lateral dimension of the tensile specimens, in which only the transducers of natural resonance frequency of $150 \mathrm{kHz}$ could be used. The ultrasonic pulse velocity was obtained by direct transmission, where the transmitter and the receiver transducers are 
located directly opposite each other on parallel surfaces. The connection of the transducers to the specimen was improved through the application of an appropriate coupling gel, in order to reduce the influence of voids between the material and the transducers. The transit time was recorded for each specimen as the average of three independent readings.

\section{Experimental results}

\subsection{Mechanical and physical properties}

The average values of the tensile and compressive strength and the modulus of elasticity for the different types of granites are indicated in Table 2 . Here, the tensile strength, $f_{t}$, and normalized fracture energy, $G f_{N I}$, are referred to mode I tensile tests, whereas the compressive strength, $f_{c}$, modulus of elasticity, $E$, and stress markers $f_{c i}$ and $f_{c d}$ describe the compressive behavior of granites. It is noted that the normalized fracture energy is given by the fracture energy divided by the tensile strength, which is also sometimes referred to as ductility.

In general, fresh granites or less weathered granites (BA, GA, RM, MC, PTA, PLA), exhibit low values of porosity, up to $1.2 \%$. The weathered granites present considerably higher values. The high porosity values of the weathered granites MDB* (7.24\%) and PTA* $(5.02 \%)$ is macroscopically associated with changes of color and a rougher surface. Although granite MDB is considered a non-weathered granite because of its white color, the value of porosity is remarkably high (5.06\%). It has been noted that the porosity of igneous rocks tends to increase up to $20 \%$ or more as the weathering degree

increases [31]. From the tests, it is also evident that the density decreases as the porosity 
increases. The values of porosity present some scatter, in opposition to density that features very low coefficients of variation.

The compressive fracture process up to peak is well described by the stress markers, $f_{c i}$ and $f_{c d}$, see Fig. 2.. The onset of the microcraking is associated to the stress level $f_{c i}$ and is followed by a nonlinear increase on the lateral strain, as well as by the nonlinearity of the volumetric strain. The unstable microcracking occurs for the crack damage stress level, $f_{c d}$, and is associated to the reversal point in the total volumetric strain diagram $\left(V_{r}\right)$. This point is connected to the maximum compaction of the specimen and to the onset of dilation, since the increase on volume generated by the cracking process is larger than the standard volumetric decrease due to the axial load.

It can be seen that there is a wide range of variation for the mechanical properties among the granites, with low to moderate levels of scatter. According to what was largely discussed in [32], the weathering state, planar anisotropy and even the grain size influence considerably the strength and elastic properties. It is clear that the weathering state leads to a significant reduction of tensile and compressive strength, as well as of the modulus of elasticity. On the other hand, the normalized fracture energy (or ductility) increases with weathering. Granites exhibit low to high anisotropy under tensile loading. Under compression, the anisotropic behavior is more moderate, which can be attributed to the fact that the macrocracks are not perfectly aligned with the plane of anisotropy (foliation or rift plane) as in case of the direct tension. 


\subsection{Ultrasonic pulse velocity}

The mean values of the UPV were obtained by averaging three measurements of the transit time, $t$, recorded during the test. After measuring the path length, $L$, the values of the velocity were calculated as UPV $=L / t$.

The mean values of the ultrasonic pulse velocity measured in the cubic specimens and the corresponding coefficients of variation are shown in Table 3. The results include the values obtained for different moisture contents, dry and saturated conditions, and for two distinct frequencies of the transducers. It should be mentioned that the results obtained in the cubic specimens are taken as reference, given the lower dimensions of the compressive and tensile specimens.

It can be observed that the differences between the values of the ultrasonic pulse velocity obtained for frequencies of 54 and $150 \mathrm{kHz}$ are very small, with a maximum of $4.5 \%$ and an average of $2 \%$. If a linear correlation is fitted to the experimental data, the velocity obtained with $150 \mathrm{kHz}$ transducers could be obtained from the velocity attained with the transducers of natural frequency of $54 \mathrm{kHz}$ by the expression $\mathrm{UPV}_{150}=$ 0.98. $\mathrm{UPV}_{54}\left(r^{2}=1.0\right)$. For practical purposes, this means that both transducers yield the same results. When frequencies of $54 \mathrm{kHz}$ are considered, the UPV values range from $1956 \mathrm{~m} / \mathrm{s}$ for granite $\mathrm{PTA}^{*}$ to $4805 \mathrm{~m} / \mathrm{s}$ for granite BA. The latter value is close to the typical values reported for fresh granites [25]. In case of saturated specimens, the values are between $3994 \mathrm{~m} / \mathrm{s}$ and $5527 \mathrm{~m} / \mathrm{s}$, which means that a narrower range of values is observed. The low scattering found reflects the homogeneity of the test materials, which belong to the same large stone block, and confirms the reliability of UPV testing. When comparing the average values of UPV obtained in the specimens with distinct shape and size, only moderate differences are found, see Fig. 3.. With the exception of 
granite PTA*, where the cubic specimens reaches values of UPV $10 \%$ and $17.5 \%$ higher (direction perpendicular and parallel to the foliation) than the ones obtained in tensile prismatic specimens, differences lower than $6.5 \%$ were always found. No significant differences were found with respect between cubic specimens and the cylindrical compressive specimens, which are always lower than $6 \%$. This means that the distinct size and shape of the specimens used in the mechanical tests leads to values of the ultrasonic pulse velocity close enough to the reference results. Therefore, statistical correlations between the UPV and the mechanical parameters measured in each specimen can be proposed.

\subsection{Analysis of the variation on the UPV}

Aiming at obtaining a better insight into the main factors that contribute to the range of variation of the ultrasonic pulse velocity among granites, internal microstructural aspects related to the planar anisotropy, weathering state and moisture content are analyzed next.

\subsubsection{Weathering state and planar anisotropy}

The comparison between the values of the ultrasonic pulse velocity measured in fresh and weathered granites is shown in Fig. 4., where the values of porosity are also indicated inside brackets. From the test results, one can observe that the weathering state influences the velocity of propagation of the ultrasonic waves through the elastic matrix of the material, for dry and saturated conditions. Apart from granite MDB and MDB*, which is hardly sensitive to weathering (as indicated above MDB and MDB* are probably both weathered), higher values of the ultrasonic velocity were obtained in less weathered granites. Among these, more remarkable differences were recorded in 
case of granites PLA and PTA. This behavior can be related to the degree of alteration that can be evaluated through the increase in the porosity. In fact, as was previously mentioned, the increase in the porosity from fresh to weathered granites means a reduction of the stiffness and strength of the granites. This can be associated to the degradation of the rock forming minerals strength and of the grain boundaries stiffness. The higher amount of voids, pores and unavoidable microfissures reflects the slower propagation of the elastic waves. Gupta and Rao [33] found progressively decreasing values of the UPV with the degree of weathering. This reduction is less significant in case of saturated specimens since pores and voids, as well as microfissures are filled with water.

Assuming that the UPV is affected by microfissuring of the material, it can be a simple and economic tool to evaluate the degree of weathering of granites, as already indicated in [31]. The theoretical value of the UPV of granite can be calculated from the modal composition and from the knowledge of the velocity of rock forming minerals. A comparison of the theoretical value with the effective measured value of the ultrasonic pulse velocity represents a measure of the rock quality. This comparison can also be an important technique to detect microfracturing in materials subjected to compressive or tensile loading. Meglis [19] reported the decreasing of the UPV as the damage due to stress induced cracking grows. During compression tests in granites, anisotropic decrease of the velocity was recorded, which is associated to the significant decrease of the velocity measured normal to the loading direction. This behavior is confirmed by the results of uniaxial compression tests conducted on three specimens of granite PLA* in the parallel and perpendicular direction to the rift plane. In Fig. 5., the evolution of the UPV with the increasing compressive stress applied in the uniaxial compression test 
given by the relation between the compressive stress and compressive strength $\left(\sigma / f_{c}\right)$ is shown. It is observed that a significant reduction of the UPV is found in the direction perpendicular to loading, whereas almost constant values are found in the direction parallel to loading. This behavior indicates material discontinuities resulting from microcracking developed in plans oriented in the direction of axial loading. It is possible to verify that the reduction on the UPV is particularly noticeable above the stress level corresponding to the crack damage stress, $f_{c d}$, which equals approximately $0.5 f_{c}$.

Under free stress conditions, the anisotropic velocity reflects the internal structure of the material related to the preferential alignment of minerals or cracks. The effect of the structural arrangement of the grains on the velocity of propagation of the ultrasonic waves concerning the planar anisotropy (foliation and quarry planes), can be observed in Fig. 6. Again with the exception of MDB and MDB*, the results stress the role of the foliation and rift planes in the velocity of propagation of the ultrasonic waves. The velocity of propagation of the UPV is higher in the direction parallel to the foliation or rift planes. Similarly to what was referred about the weathering effect, also the anisotropy resulting from the internal structure is lowered by water saturation.

\subsubsection{Moisture content}

As reported in [34], the compressional wave velocities exhibit distinct values according to the different pore fluid present in the rock, and.saturation increases compressional velocities. Winkler and Murphy [35] indicate from Biot's theory that acoustic waves create relative motion between the fluid and the solid skeleton due to inertial effects. When the matrix is accelerated, the fluid lags behind, from which results viscous dissipation of acoustic energy. The effect of the pore fluid saturation on the velocity is 
however dependent on the frequency of the signal. At higher frequencies, the viscous wavelength is very small and the fluid and solid are essentially decoupled, resulting in a maximum velocity. On the contrary, the velocity is minimal at low frequencies, when both fluid and solid are moving in phase.

In this work the effect of the water saturation is investigated by comparing the values of the UPV found in dry and saturated specimens. This analysis shows that moisture content has a remarkable influence on the velocity of propagation of the ultrasonic waves. The results indicate a clear tendency for dry specimens to exhibit much lower values of the UPV regarding the ones obtained in saturated specimens. Similar tendency was found by [33], for granites and basalts. Fig. 7a shows that the values of the UPV obtained in saturated and dry specimens are well correlated $\left(r^{2}=0.88\right)$. This means that the values of the ultrasonic pulse velocity in saturated specimens can be obtained with reasonable accuracy from the values recorded in dry specimens. In spite of the large scatter, the difference of the UPV for both moisture conditions appears to have some relation with the porosity of granites, see Fig. 7.b. The increase of the UPV from dry to saturated conditions increases as the porosity increases. For moderate and high porosities there are large variations of the $U P V_{d r y}$ to $U P V_{\text {sat }}$ ratio, which, to certain extent, can be explained by the attenuation of the anisotropy under saturated conditions. Fig. 8 shows the increase of the UPV measured on saturated specimens with respect to dry specimens defined by the following expression:

$\Delta U P V_{s a t}=\frac{U P V_{s a t}-U P V_{d r y}}{U P V_{d r y}}$

In low porosity granites like BA and GA, the difference on the ultrasonic pulse velocity measured in dry and saturated specimens is of 14.1 and $17.4 \%$ respectively, whereas in granite RM and MC, the saturated specimens exhibit 30.5 and $35.0 \%$ larger values than 
dry specimens. Reduction of approximately $30 \%$ of the dry velocity was recorded in granite PTA. A reduction of the UPV in dry specimens with saturation of about $20-30 \%$ was reported by [36] in low porosity rocks.

Higher deviations were found in high porosity granites such as granites AF, PTA*, MDB and MDB*, where an increase of the ultrasonic pulse velocity in saturated specimens reaches a maximum of $105 \%$ in granite $\mathrm{PTA}^{*}$, in the direction perpendicular to the rift plane. The increase in the velocity in saturated specimens depends on the direction of measurement and, with the exception of granite MDB, granites exhibit a more noticeable increase of the UPV in saturated specimens in the direction perpendicular to the foliation or rift planes. As previously mentioned, the consequence of this behavior is the reduction of the anisotropy of granites under saturated conditions, which seems to be related with a loss of sensitivity of the UPV technique to detect major discontinuities associated to pre-existing microfissures aligned in the direction parallel to the rift plane or to foliation plane.

\section{Correlations between UPV and physical and mechanical properties}

As addressed above elastic properties are usually necessary in the evaluation of the performance of built structures and UPV is commonly used in the estimation of the strength of concrete [37]. Concerning the assessment of the rock properties by means of simple non destructive techniques, different results revealed the dependence of the mechanical properties, namely the modulus of elasticity and compressive strength, on UPV $[10,38]$.

The present section aims at obtaining statistical correlations that enable the estimation of granite mechanical properties from UPV. The experimental data collected in the 
present testing program includes UPV measurements from cubic, prismatic tensile and cylindrical compressive specimens. The relationship between the velocity of the longitudinal ultrasonic waves and the tensile and compressive strength are displayed in Fig. 9a and Fig. 9b, respectively. A reasonable nonlinear correlation was found between the tensile strength and ultrasonic velocity $\left(r^{2}=0.89\right)$, meaning that ultrasonic pulse velocity can provide a reliable preliminary estimation of the tensile strength. High strength granites have associated high values of velocity. The compressive strength can only be roughly estimated by the linear expression shown in Fig. 9b, since the coefficient of correlation corresponding to the linear function found between both variables is lower $\left(r^{2}=0.72\right)$. This statistical correlation is, to great extent, affected by the anisotropy of the granites, particularly, of granites PLA and PLA*. As discussed previously, the application of compressive loads in the direction parallel to the rift plane, which is defined by the preferential alignment of feldspar megacrystals and the preferential alignment of the microfissures, leads to tensile stress concentrations at the tip of the potential microfissures, resulting in a reduction of the compressive strength. However, the UPV presents rather high values in this direction, since it is in the perpendicular direction to the foliation that the pre-existing microfractures discontinuities are detected. If the values concerning the granites PLA and PLA* were excluded from the experimental data, a linear function $f_{c}=0.0446 U P V_{d r y}-46.70$ would be found for the relationship between the compressive strength and the ultrasonic pulse velocity, with a mucher higher coefficient of determination $\left(r^{2}=0.85\right)$. But this correlation should only be used for rather isotropic granites. It is noted that linear correlations between the compressive strength and the UPV were given in [38] for granites and in [10] for several types of rocks. 
The relation between the UPV and the modulus of elasticity is displayed in Fig. 10. The significant linear correlation achieved between the modulus of elasticity and the UPV $\left(r^{2}=0.84\right)$ confirms the expected relation between both properties. It should be noticed that the propagation velocity depends on the dynamic modulus of elasticity of the continuum medium.

In addition to previous researchers, relations between the UPV and compressive and tensile fracture properties are also investigated. With respect to compressive loading, linear fittings of the experimental data composed by the UPV and the stress markers that characterize the pre-peak fracture process are proposed, see Fig. 11. The linear functions show that rough estimations of the crack initiation and crack damage stress levels, $f_{c i}$ and $f_{c d}$, can be obtained from the UPV. The coefficient of correlation would increase considerably if the values concerning the granite PLA (perpendicular direction to rift plane) were excluded from the data.

Reasonable nonlinear correlations were found between ultrasonic pulse velocity and the mode I normalized fracture energy, $G_{f N}$. In spite of the scattered data, there is a clear tendency for the UPV to exhibit higher values in case of more brittle materials, seeFig. 12.

The reasonable relations obtained between UPV and tensile and compressive fracture parameters can be, to a certain extent, explained by the good correlations achieved between the compressive and tensile fracture properties with the corresponding peak stress $[27,29]$. As a main result, it is important to stress the possibility of estimating the compressive and tensile fracture behavior of granites by simply measurement of the UPV. 
The relations between the UPV and the physical parameters, porosity and density, are illustrated in Fig. 13. Both correlations are characterized by large scatter of the data, which to a certain extent is associated to the anisotropy of some granites. However, a reasonable nonlinear correlation was found between UPV and porosity $\left(r^{2}=0.74\right)$. If one considers the values of the UPV in saturated conditions, the nonlinear correlation with the porosity is given by $U P V_{\text {sat }}=5004 \eta^{-0.123}\left(r^{2}=0.78\right)$. For the density, despite the large scatter, there is still a positive trend with the UPV.

\section{Conclusions}

In order to obtain a better insight about the adequacy of using the ultrasonic pulse velocity (UPV) as a simple and economical nondestructive technique to predict the elastic and strength properties of granite, a large experimental testing programme was set-up. Cubic, prismatic tensile and cylindrical compressive specimens with distinct size were considered under different moisture conditions, namely, oven dried and saturated. Two distinct natural resonance frequencies of the transducers were also considered. From the results, it was observed that although no significant differences were obtained between frequency transducers, UPV measured with frequency of $150 \mathrm{kHz}$ exhibit slightly lower values than $54 \mathrm{kHz}$ transducers. Also specimens of smaller size (tensile specimens) present slightly lower values of the UPV.

Factors like weathering state and moisture content were found to affect remarkably the values of the UPV. Weathered granites exhibit lower values for UPV and saturated granites exhibit higher values for UPV. In addition, the internal microstructure related to planar foliation or rift plane leads to remarkable anisotropy of the UPV. Higher values of velocity were recorded in the direction parallel to the foliation or rift planes. 
Anisotropy can be, to a great extent, hidden by water saturation of the specimens. This moisture condition leads to a loss of sensitivity to detect internal free stress microcracking that induces anisotropy. Therefore, UPV appears to be a simple nondestructive technique of evaluating the internal anisotropy only of dry granites. The significant statistical correlations that were established between the ultrasonic pulse velocity and the mechanical properties, namely tensile strength, compressive strength, modulus of elasticity and fracture values, indicate that these parameters can be reasonably estimated by means of this nondestructive method. In particular, the statistical correlations obtained between UPV and fracture parameters seem to be novel in the literature and can be used for an estimation of the fracture behavior of granites in compression and tension.

\section{References}

[1] L. Binda, G. Lensi, A. Saisi, NDE of masonry structures: use of radar tests for the characterization of stone masonries, NDT\&E International, 31 (6), 411-419, 1998.

[2] L. Topczewski, F., Fernandes, P.J.S, Cruz, P.B., Lourenço, Practical implications of GPR investigation using 3D data reconstruction and transmission tomography, Journal of Building Appraisal, 3 (1), 59-76, 2007.

[3] M. Schuller, M. Berra, R. Atkinson, L. Binda, Acoustic tomography for evaluation of unreinforced masonry, Construction and Building Materials, 11 (3), 199-204, 1997.

[4] F. Fernandes, P.B., Lourenço, Evaluation of the Compressive Strength of Ancient Clay Bricks Using Microdrilling, Journal of Materials in Civil Engineering, ASCE, 19 (9), 791-800, 2007. 
[5] M. Hassan, O. Burdet, R. Favre, Ultrasonic measurements and static load tests in bridge evaluation, NDT\&E International, 28 (6), 331-337, 1995.

[6] D.A. Sack, L.D. Olson, Advanced NDT methods for evaluating concrete bridges and other structures, NDT\&E International, 28 (6), 349-357, 1995.

[7] Lourenço, P.B., Feio, A., Machado, J.S., Chestnut wood in compression perpendicular to the grain: Non-destructive correlations for new and old wood, Construction and Building Materials, 21 (8), 1617-1627, 2007.

[8] Feio, A., Lourenço, P.B., Machado, J.S., New and old chestnut wood parallel to the grain: Mechanical behaviour and non-destructive evaluation, International Journal of Architectural Heritage, 3 (1), 2007.

[9] E. Uchida, Y. Ogawa, N. Maeda, T. Nakagawa, Deterioration of stone materials in the Angkor monuments, Cambodia, Engineering Geology, 55, 101-112, 1999.

[10] S. Kahraman, Evaluation of simple methods for assessing the uniaxial compressive strength of rock, International Journal of Rock Mechanics and Mining Sciences, 38 (7), 981-994, 2001.

[11]E.Yasar, Y. Erdoğan, Correlating sound velocity with density, compressive strength and Young modulus of carbonate rocks, International Journal of Rock Mechanics and Mining Sciences, 41 (5), 871-875, 2004a.

[12]M. Saka, T. Uchikawa, Simplified NDE of a closed vertical crack using electronics, NDT\&E International, 28 (5), 289-296, 1995.

[13]H.-W.Reinhardt, C. Große, A. Herb, Ultrasonic monitoring of setting and hardening of cement mortar, Materials and Structures, 33, 580-583, 2000. 
[14] V.S. Kolluru, J.P. Mohsen, C.K Shaw, S.P. Shah, Ultrasonic technique for monitoring concrete strength gain at early age, $A$ CI Materials Journal, 99 (2), 458$462,2002$.

[15] Y. Akkaya, T. Voigt, K.V Subramaniam, S.P. Shah, Nondestructive measurement of concrete strength gain by an ultrasonic wave reflection method, Materials and Structures, 36, 507-514, 2003.

[16] Y. Lin, C.-P Lay, T. Yen, Prediction of ultrasonic pulse velocity (UPV) in concrete, ACI Materials Journal, 100 (1), 21-28, 2003.

[17] J.S. Popovics, NDE techniques for concrete and masonry structures, Progress in Structural Engineering and Materials, 5 (2), 49-59, 2003.

[18] E. Grinzato, S. Marinetti, P.G. Bison, M. Concas, S. Fais, Comparison of ultrasonic velocity and IR thermography for the characterization of stones, Infrared Physics \& Technology, 46, 63-68, 2004.

[19] I.L. Meglis, T. Chow, C.D. Martin, R.P. Young, Assessing in situ microcrack damage using ultrasonic velocity tomography, International Journal of Rock Mechanics and Mining Sciences, 42 (1), 25-34, 2005.

[20] S. Kahraman, Estimating the direct P-wave velocity value of intact rock from indirect laboratory measurements, International Journal of Rock Mechanics and Mining Sciences, 39 (1), 101-104, 2002.

[21] I.W.Farmer, Engineering behavior of rocks, $2^{\text {nd }}$ edition, Chapman and Hall, 1983. ISBN 0412139804.

[22] E. Eberhardt, D. Stead, B. Stimpson, Quantifying progressive pre-peak brittle fracture damage in rock during uniaxial compression, International Journal of Rock Mechanics and Mining Sciences, 36, 361-380, 1999. 
[23] W.S.Pettitt, M.S. King, Acoustic emission and velocities associated with the formation of sets of parallel fractures in sandstones, SINOROCK2004 Symposium, Paper1A 25, CD-ROM, 2004.

[24] A. Mirmiram, Y. Wei, Damage assessment of FRP-encased concrete using ultrasonic pulse velocity, Journal of Engineering Mechanics, 127 (2), 126-135, 2001.

[25] R. Přikril, Some microstructural aspects of strength variation in rocks. Int J Rock Mech Min Sci 2001; 38: 671-682.

[26] ISRM Suggested Methods. Suggested method for determining tensile strength of rock materials. ET Brown, Ed. Oxford: Pergamon Press, 1981.

[27] G. Vasconcelos, P.B. Lourenço, C.A.S. Alves, J. Pamplona, Experimental characterization of the tensile behaviour of granites, International Journal of Rock Mechanics and Mining Sciences, 2007 (in press).

[28] ASTM D2938-95 - Standard test method for unconfined compressive strength of intact rock cores specimens, American Society for Testing Materials, 2002.

[29] G. Vasconcelos, Experimental investigations on the mechanics of stone masonry: characterization of granites and behaviour of ancient masonry walls. $\mathrm{PhD}$ Thesis, University of Minho, 2005. Available from www.civil.uminho.pt/masonry.

[30] ASTM D2845-05 - Standard test method for laboratory determination of pulse velocities and ultrasonic elastic constants of rock, American Society for Testing Materials, 2005.

[31] R. Goodman, Introduction to rock mechanics, 2nd edn, John Wiley \& Sons, Inc., New York, 1989. ISBN 0471617180 
[32] G. Vasconcelos, P.B. Lourenço, C.A.S. Alves, J. Pamplona, Analysis of weathering and internal texture on the engineering properties of granites, $11^{\text {th }}$ International Congress of the International Society of Rock Mechanics, Workshop W3-Preservation of Natural Stone and Rock Weathering, 75-83, 2007.

[33] A.S. Gupta, K.S. Rao, Index properties of weathered rocks: inter-relationships and applicability, Bulletin Engineering Geology and Environment, 57, 161-172, 1998.

[34] Z. Wang, M.L.Battle, A. Nur, Effect of different pore fluids on seismic velocities in rocks, Canadian Journal of Exploration Geophysics, 26, 104-112, 1990.

[35] K.W.Winkler, W.F. Murphy III, Acoustic velocity and attenuation in porous rocks, Rock Physics and Phase Relations, American Geophysical Union, 20-34, 1995.

[36] T. Todd, G. Simmons, Effect of the pore pressure on the velocity of compressional waves in low-porosity rocks, Journal of Geophysical Research, 10, 3731-3743, 1972.

[37] C. Komloš, S. Popovics, T. Nürnbergerová, B. Babál, J.S. Popovics, Ultrasonic pulse velocity test of concrete properties as specified in various standards, Cement and Concrete Composites, 18 (5), 357-364, 1996.

[38] A. Tuğrul, I.H. Zarif, Correlation of mineralogical and textural characteristics with engineering properties of selected granitic rocks from Turkey, Engineering Geology, 51, 303-317, 1999. 
Table 1

: Brief description of granites tested and loading directions

\begin{tabular}{|c|c|c|}
\hline $\begin{array}{l}\text { Granite } \\
\text { Designation }\end{array}$ & Description & Loading Directions \\
\hline $\mathbf{A F}$ & $\begin{array}{l}\text { Fine to medium-grained two-mica } \\
\text { granite }\end{array}$ & $\begin{array}{l}\text { Parallel and perpendicular to } \\
\text { the foliation plane }\end{array}$ \\
\hline MC & $\begin{array}{l}\text { Coarse-grained porphyritic } \\
\text { biotite granite }\end{array}$ & Parallel to the rift plane \\
\hline $\begin{array}{l}\text { MDB } \\
\text { MDB* }\end{array}$ & $\begin{array}{l}\text { Medium-grained two- mica } \\
\text { granite }\end{array}$ & $\begin{array}{l}\text { Parallel and perpendicular to } \\
\text { the foliation plane }\end{array}$ \\
\hline $\mathbf{R M}$ & Medium-grained biotite granite & Parallel to the rift plane \\
\hline GA, GA* & $\begin{array}{l}\text { Fine to medium-grained, with } \\
\text { porphyritic trend, two mica } \\
\text { granite }\end{array}$ & Parallel to the rift plane \\
\hline $\mathbf{B A}$ & $\begin{array}{l}\text { Fine to medium-grained } \\
\text { porphyritic biotite granite }\end{array}$ & Parallel to the rift plane \\
\hline $\begin{array}{l}\text { PTA } \\
\text { PTA* }\end{array}$ & $\begin{array}{l}\text { Fine to medium-grained two-mica } \\
\text { granite }\end{array}$ & $\begin{array}{l}\text { Parallel and perpendicular to } \\
\text { the foliation and rift plane }\end{array}$ \\
\hline $\begin{array}{l}\text { PLA } \\
\text { PLA* }\end{array}$ & $\begin{array}{l}\text { Medium to coarse-grained } \\
\text { porphyritic biotite granite }\end{array}$ & $\begin{array}{l}\text { Parallel and perpendicular to } \\
\text { the rift plane }\end{array}$ \\
\hline
\end{tabular}


Table 2

: Mechanical parameters characterizing the tensile and compressive behavior of granites. The coefficient of variation is indicated inside brackets

\begin{tabular}{|c|c|c|c|c|c|c|c|}
\hline Granite & Porosity (\%) & $f_{t}\left(\mathrm{~N} / \mathrm{mm}^{2}\right)$ & $G_{f N}(\mathrm{~mm})$ & $f_{c}\left(\mathrm{~N} / \mathrm{mm}^{2}\right)$ & $E\left(\mathrm{~N} / \mathrm{mm}^{2}\right)$ & $f_{c i}\left(\mathrm{~N} / \mathrm{mm}^{2}\right)$ & $f_{c d}\left(\mathrm{~N} / \mathrm{mm}^{2}\right)$ \\
\hline BA & $0.51(12.9)$ & $8.08(11.4)$ & $0.023(14.7)$ & $148.5(4.8)$ & $59939 \quad(5.2)$ & $55.1\left(0.36 f_{c}\right)$ & $102.2\left(0.66 f_{c}\right)$ \\
\hline GA & $0.47 \quad(6.1)$ & $6.01(11.1)$ & $0.025(22.0)$ & $135.7(5.0)$ & $52244 \quad(2.3)$ & $50.0\left(0.37 f_{c}\right)$ & $96.2\left(0.71 f_{c}\right)$ \\
\hline GA* $^{*}$ & 3.56 (2.6) & $3.52(12.3)$ & 0.058 (23.2) & $89.5 \quad(2.5)$ & $35088 \quad(3.3)$ & $25.1\left(0.28 f_{c}\right)$ & $43.2\left(0.49 f_{c}\right)$ \\
\hline RM & $0.74 \quad(9.6)$ & $4.51 \quad(9.3)$ & $0.033(14.1)$ & $159.8(2.5)$ & 58926 (1.8) & $52.4\left(0.33 f_{c}\right)$ & $123.3\left(0.78 f_{c}\right)$ \\
\hline MC & $0.87 \quad(4.3)$ & $5.23(6.3)$ & $0.043(21.0)$ & $146.7(2.8)$ & 63794 (5.6) & $58.5\left(0.39 f_{c}\right)$ & $120.9\left(0.81 f_{c}\right)$ \\
\hline$A F \perp$ foliation & & 2.34 (11.5) & $0.077(19.1)$ & $66.7 \quad(7.8)$ & $15748 \quad(7.2)$ & $17.5\left(0.26 f_{c}\right)$ & $29.1 \quad\left(0.43 f_{c}\right)$ \\
\hline AF // foliation & $3.16 \quad(3.2)$ & $3.04 \quad(3.0)$ & $0.067(19.8)$ & $68.9 \quad(5.6)$ & $18954 \quad(6.9)$ & $15.8\left(0.23 f_{c}\right)$ & $30.1 \quad\left(0.44 f_{c}\right)$ \\
\hline MDB $\perp$ foliation & & $2.36 \quad(5.4)$ & $0.111(17.5)$ & $49.7 \quad(5.2)$ & $15886(13.5)$ & $14.5\left(0.30 f_{c}\right)$ & $21.8 \quad\left(0.45 f_{c}\right)$ \\
\hline MDB // foliation & $5.06 \quad(7.5)$ & 2.20 & $0.113(17.8)$ & $44.8 \quad(2.8)$ & $11600 \quad(4.2)$ & $11.8\left(0.26 f_{c}\right)$ & $17.8\left(0.40 f_{c}\right)$ \\
\hline MDB* $\perp$ foliation & $724(34)$ & 1.83 & 0.147 (15.7) & $35.2 \quad(3.4)$ & $11028(12.0)$ & $9.7\left(0.27 f_{c}\right)$ & $15.2\left(0.43 f_{c}\right)$ \\
\hline MDB* // foliation & $1.24(3.4)$ & $1.97 \quad(5.3)$ & $0.126(12.1)$ & $26.0 \quad(7.1)$ & $12243(13.6)$ & $6.8 \quad\left(0.27 f_{c}\right)$ & $10.7\left(0.43 f_{c}\right)$ \\
\hline PTA $\perp$ foliation & & $4.15(14.1)$ & $0.044(21.7)$ & $119.1(3.1)$ & $40526 \quad(3.1)$ & $30.1\left(0.25 f_{c}\right)$ & $75.4\left(0.63 f_{c}\right)$ \\
\hline PTA // foliation & $1.17 \quad(2.8)$ & $4.90(15.6)$ & $0.042(12.0)$ & $109.1(7.3)$ & 41504 (1.6) & $27.0\left(0.24 f_{c}\right)$ & $58.3\left(0.53 f_{c}\right)$ \\
\hline PTA $^{*} \perp$ rift plan & & $1.56(11.3)$ & $0.151(19.4)$ & $60.4 \quad(4.8)$ & $15008 \quad(7.1)$ & $14.1\left(0.24 f_{c}\right)$ & $31.4\left(0.53 f_{c}\right)$ \\
\hline PTA* // rift plan & $5.02 \quad(7.6)$ & 2.12 & 0.124 (13.6) & $50.2(11.1)$ & 18168 (3.3) & $14.7\left(0.29 f_{c}\right)$ & $26.6\left(0.52 f_{c}\right)$ \\
\hline PLA $\perp$ rift plan & $084 \quad(58)$ & $2.79(10.5)$ & $0.053(25.0)$ & $147.0(2.6)$ & $53737 \quad(2.8)$ & $45.1\left(0.31 f_{c}\right)$ & $113.3\left(0.77 f_{c}\right)$ \\
\hline PLA // rift plan & $0.84 \quad(5.8)$ & $6.31(13.2)$ & $0.040(24.6)$ & $125.2(6.1)$ & $58180 \quad(2.6)$ & $40.8\left(0.33 f_{c}\right)$ & $85.9\left(0.70 f_{c}\right)$ \\
\hline $\mathbf{P L A} * \perp$ rift plan & & $1.91(11.1)$ & 0.085 (18.5) & $88.5 \quad(4.2)$ & 28981 (1.6) & $26.3\left(0.30 f_{c}\right)$ & $48.5 \quad\left(0.55 f_{c}\right)$ \\
\hline PLA* // rift plan & $1.55 \quad(7.7)$ & $3.86 \quad(5.1)$ & 0.065 (13.5) & $76.9 \quad(3.2)$ & $41607 \quad(7.6)$ & $19.7\left(0.26 f_{c}\right)$ & $37.8\left(0.49 f_{c}\right)$ \\
\hline
\end{tabular}


Table 3

: Mean values of the ultrasonic pulse velocity obtained in cubic specimens. Coefficient of variation is indicated inside brackets $(\%)$

\begin{tabular}{|c|c|c|c|c|}
\hline \multirow{2}{*}{ Granite } & \multicolumn{2}{|c|}{ Dry specimens } & \multicolumn{2}{|c|}{ Saturated specimens } \\
\hline & $\begin{array}{l}U P V_{54} \\
(\mathrm{~m} / \mathrm{s})\end{array}$ & $\begin{array}{c}U P V_{150} \\
(\mathrm{~m} / \mathrm{s})\end{array}$ & $\begin{array}{l}U P V_{54} \\
(\mathrm{~m} / \mathrm{s})\end{array}$ & $\begin{array}{c}U P V_{150} \\
(\mathrm{~m} / \mathrm{s})\end{array}$ \\
\hline $\mathrm{BA}$ & $4804(1.5)$ & $4776 \quad(1.7)$ & $5527 \quad(1.0)$ & $5457(1.1)$ \\
\hline GA & $4593 \quad(1.0)$ & 4556 & 5423 (1.4) & $5359(1.5)$ \\
\hline $\mathrm{GA}^{*}$ & 3244 (2.1) & $3203 \quad(2.4)$ & $4598(0.97)$ & $4505(1.4)$ \\
\hline $\mathrm{RM}$ & $4104 \quad(4.0)$ & $4037 \quad(4.1)$ & 5369 (1.3) & $5266(1.9)$ \\
\hline $\mathrm{MC}$ & 4083 (1.1) & $3986(0.85)$ & $5489(0.89)$ & $5361(1.1)$ \\
\hline $\mathrm{AF} \perp$ foliation plan & 2256 & $2186 \quad(6.0)$ & $4276 \quad(2.0)$ & $4163(1.8)$ \\
\hline $\mathrm{AF} / /$ foliation & $2572 \quad(3.7)$ & 2523 & $4410 \quad(4.7)$ & $4310(4.8)$ \\
\hline $\mathrm{MDB} \perp$ foliation & 2488 (1.5) & 2426 & $4041 \quad(1.5)$ & $3888(2.1)$ \\
\hline MDB // foliation & $2241 \quad(2.7)$ & 2181 & 3994 (4.2) & $3805(5.7)$ \\
\hline $\mathrm{MDB}^{*} \perp$ foliation & 2340 & 2273 & 4025 & $3933(3.1)$ \\
\hline MDB* // foliation & $2341(0.76)$ & $2301(0.80)$ & 4029 & $3894(2.5)$ \\
\hline PTA $\perp$ foliation & $3278(0.53)$ & $3210(0.26)$ & $4723 \quad(2.4)$ & $4576(2.8)$ \\
\hline PTA // foliation & $3585(0.35)$ & $3567 \quad(0.5)$ & $4873 \quad(2.0)$ & $4779(2.4)$ \\
\hline $\mathrm{PTA}^{*} \perp$ rift plan & $1956(17.8)$ & $1899(18.5)$ & $4024 \quad(7.2)$ & $3874(9.0)$ \\
\hline PTA* // rift plan & $2545(12.5)$ & $2495(12.2)$ & $4032 \quad(5.4)$ & $3907(7.0)$ \\
\hline $\mathrm{PLA} \perp$ rift plan & $2743(1.8)$ & $2626 \quad(2.2)$ & 4706 & $4602(5.0)$ \\
\hline PLA // rift plan & 4162 (2.1) & 4037 & 5421 (2.9) & $5268(2.3)$ \\
\hline $\mathrm{PLA}^{*} \perp$ rift plan & 2650 & 2543 & $4522(5.5)$ & $4294(6.2)$ \\
\hline PLA* // rift plan & $3720 \quad(2.3)$ & 3595 & $4981 \quad(2.7)$ & $4851(2.9)$ \\
\hline
\end{tabular}




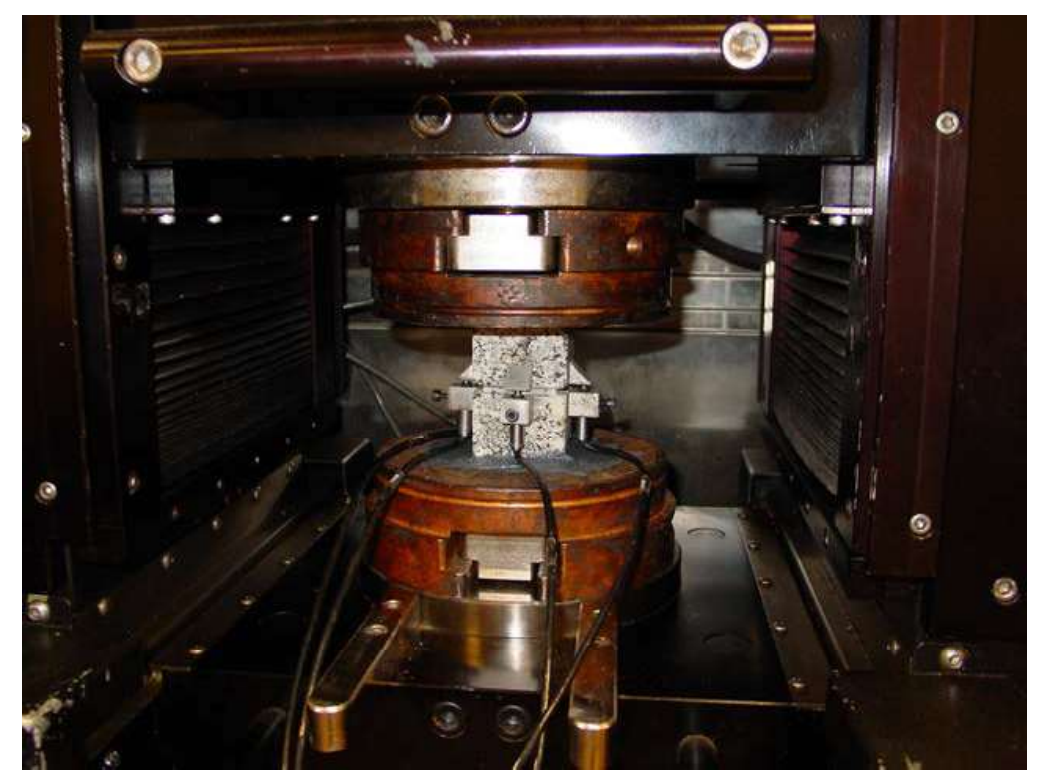

(a)

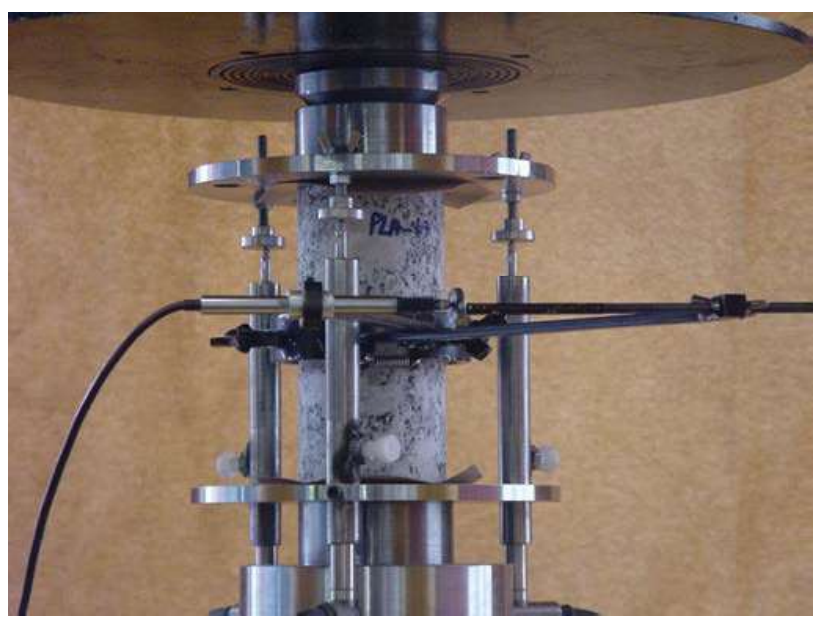

(b)

Fig. 1

. Test setup for mechanical characterization; (a) Direct tensile tests; (b) Uniaxial compressive tests 


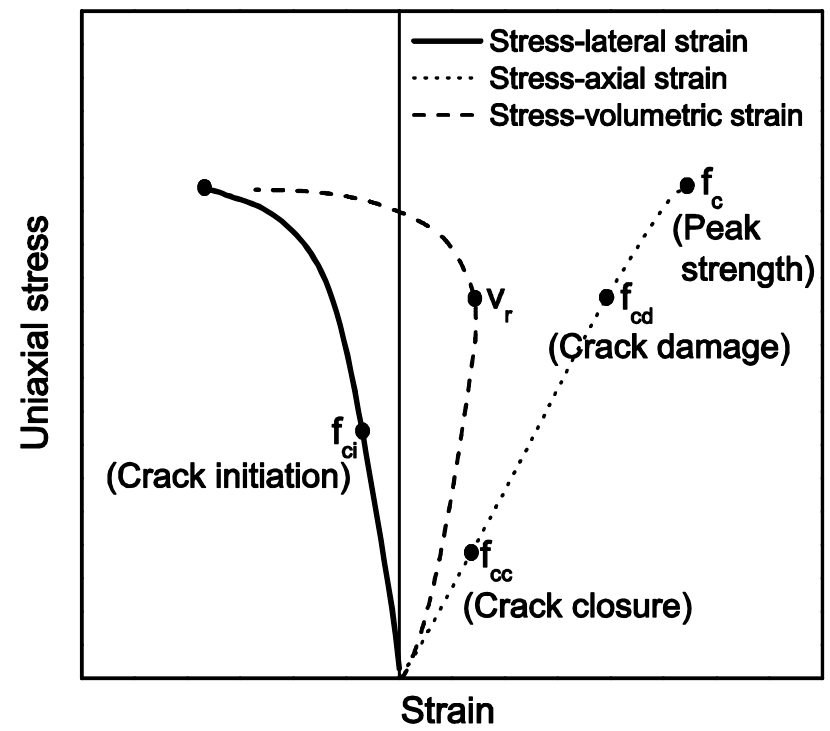

Fig. 2.

Evolution of the fracture process under uniaxial compression in a typical stress-displacement diagram up to peak load 


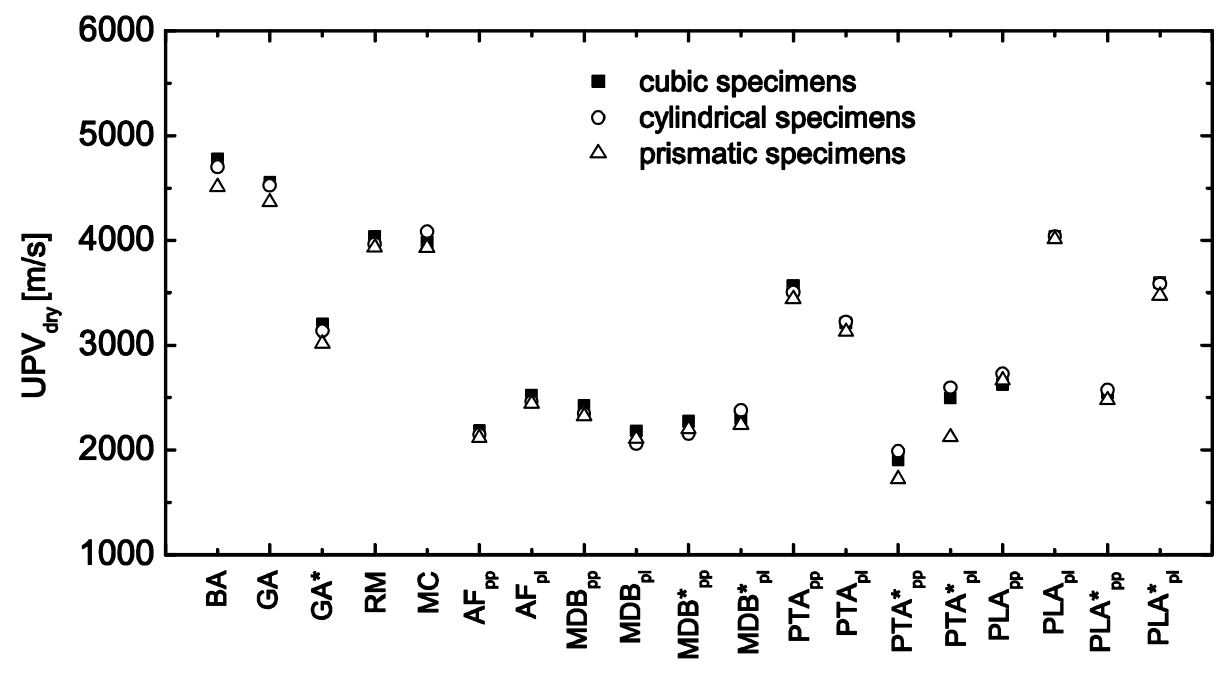

Fig. 3.

Comparison of the $\mathrm{UPV}_{\text {dry }}$ among the specimens with distinct size and shape 


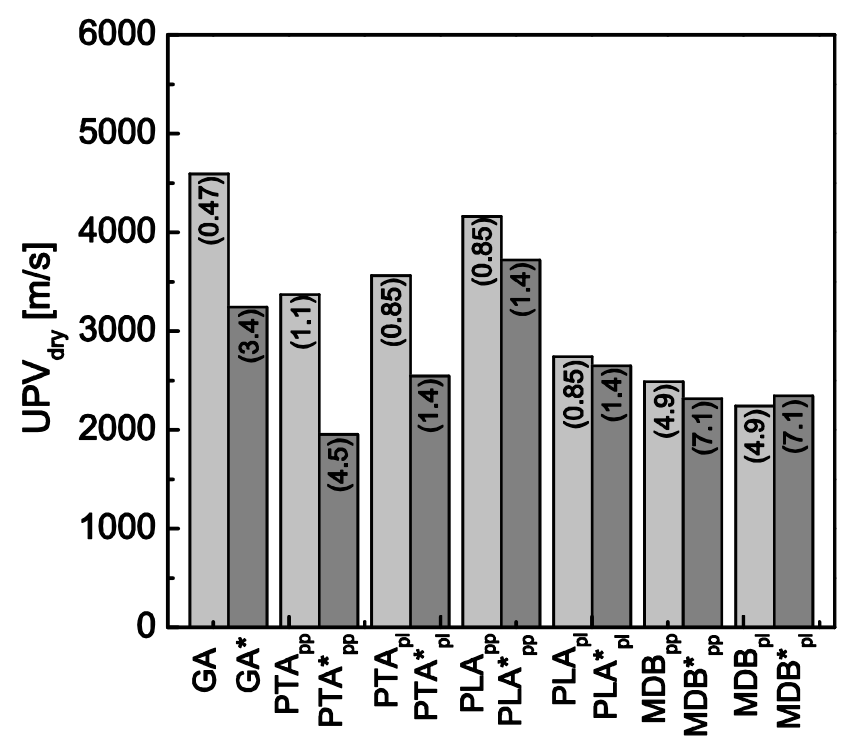

(a)

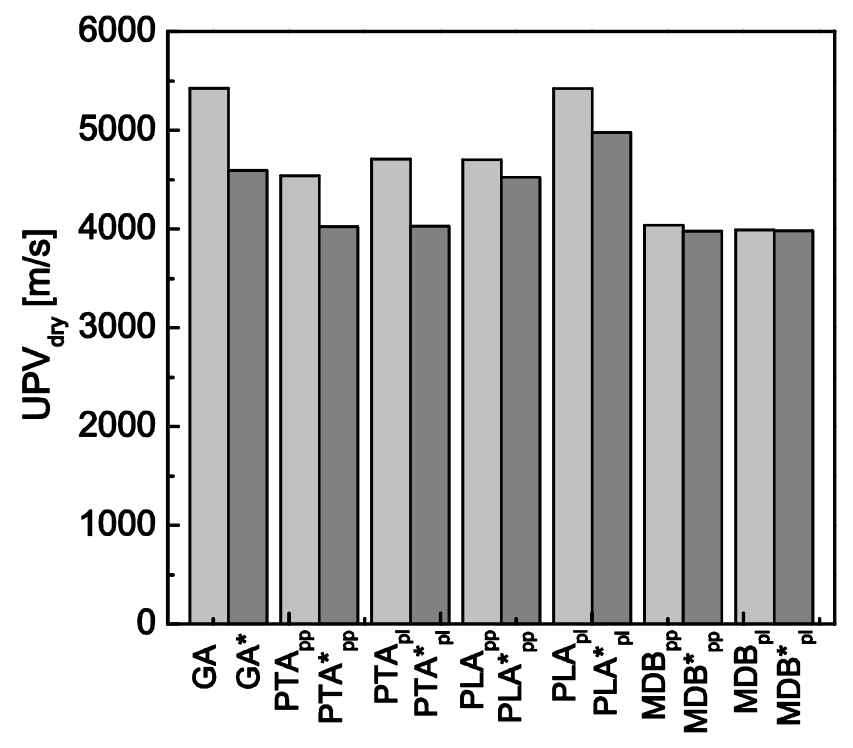

(b)

Fig. 4.

Comparison of the ultrasonic pulse velocity between fresh and weathered granites using $54 \mathrm{kHz}$ transducers; (a) dry cubic specimens; (b) saturated cubic specimens 


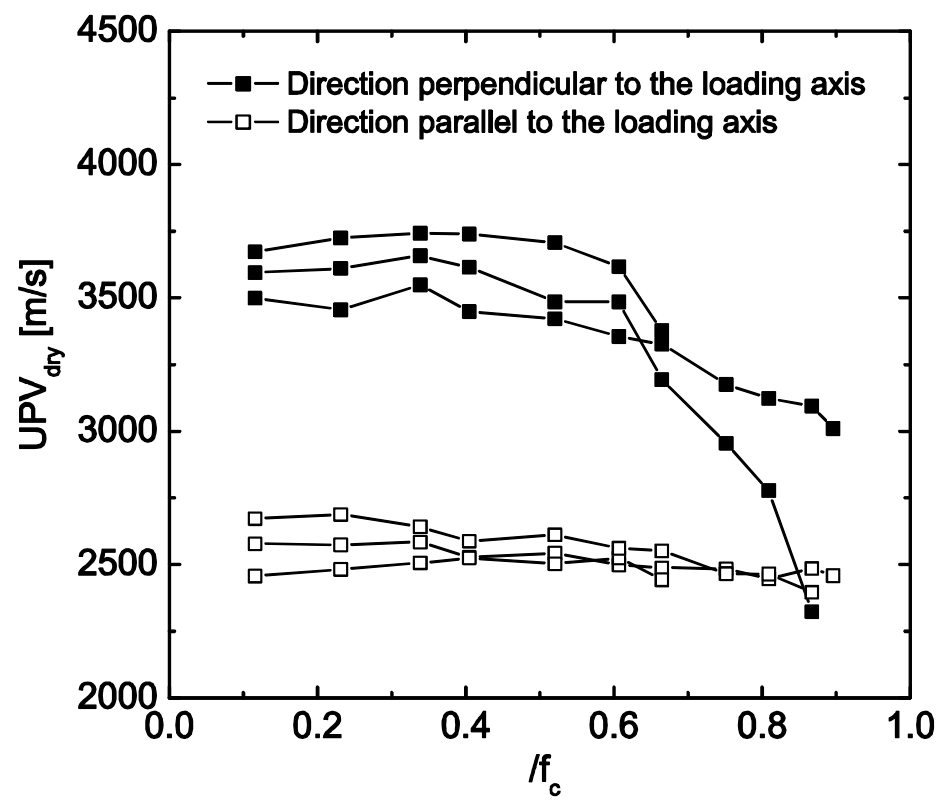

Fig. 5.

Evolution of the ultrasonic pulse velocity for granite PLA* under increasing uniaxial compressive stress 


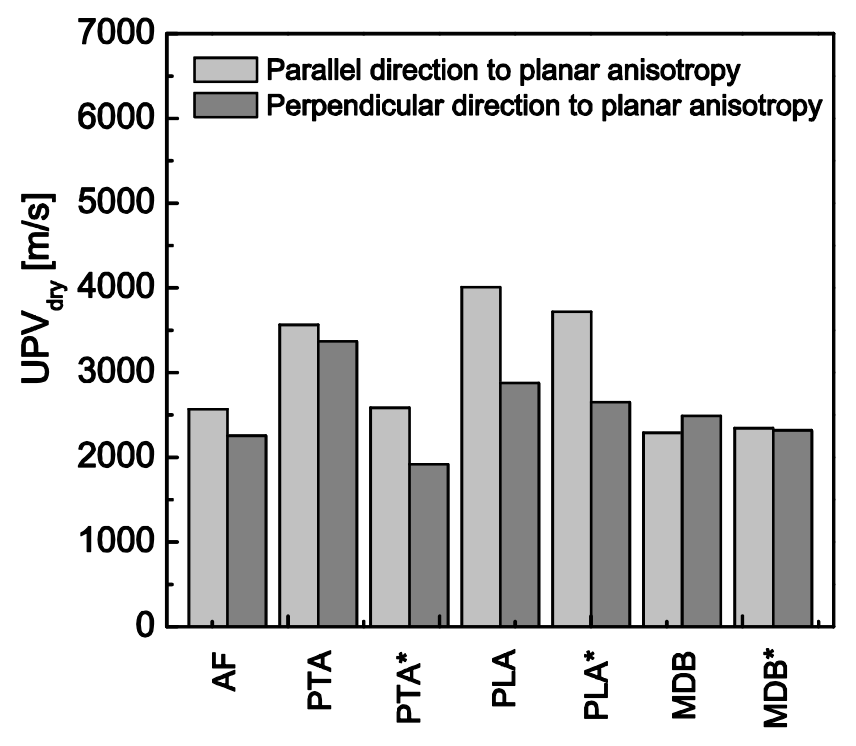

(a)

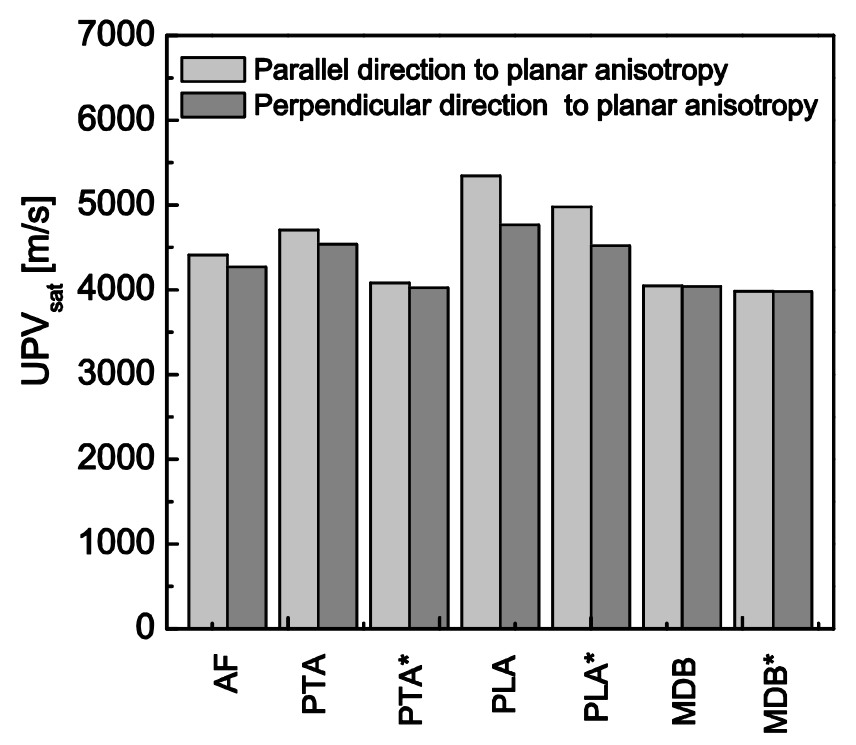

(b)

Fig. 6 .

Evaluation of the influence of planar anisotropies on the ultrasonic pulse velocity; (a) dry cubic specimens; (b) saturated cubic specimens 


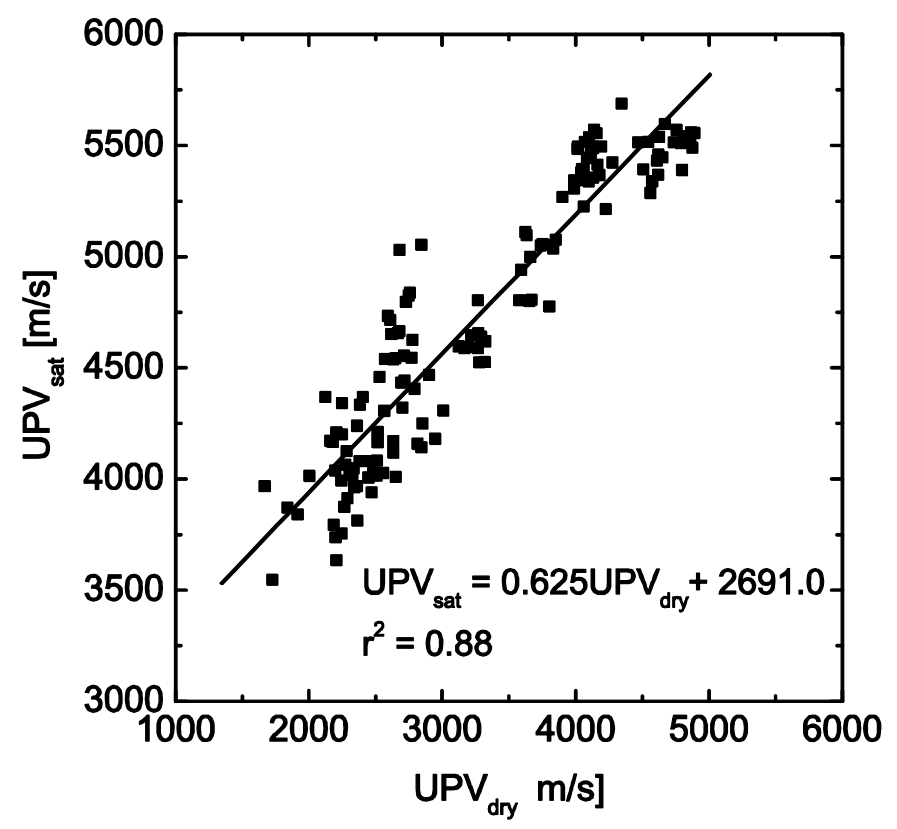

(a)

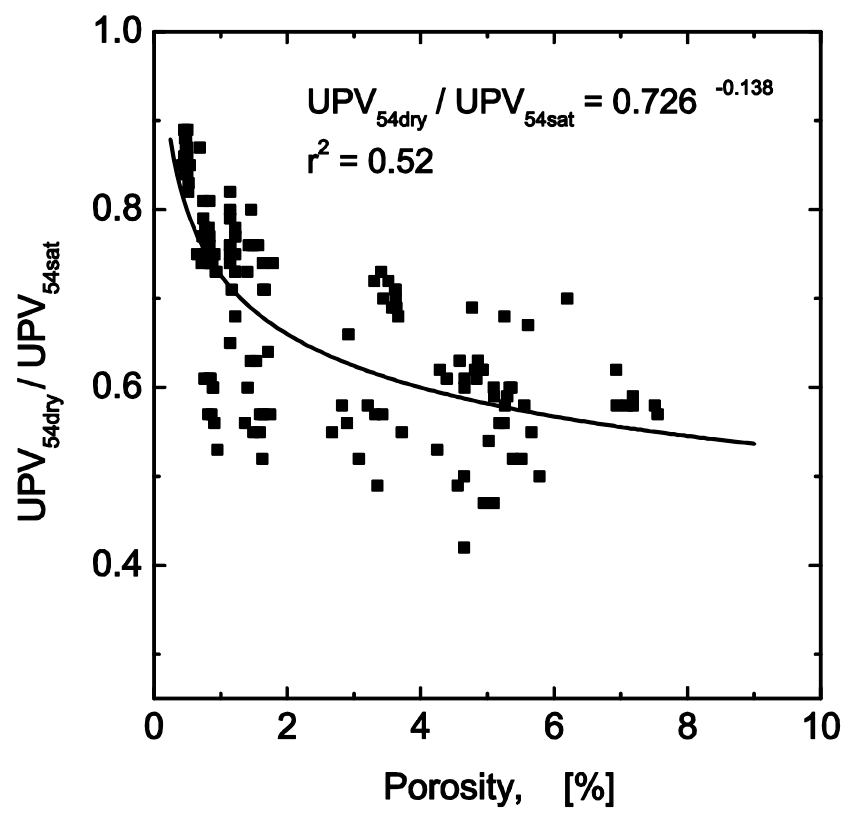

(b)

Fig. 7.

Influence of the moisture state on the ultrasonic pulse velocity; (a) $U P V_{d r y}$ vs. $U P V_{s a t}$ (b) porosity vs. $U P V_{d r y} / U P V_{\text {sat }}$ ratio 


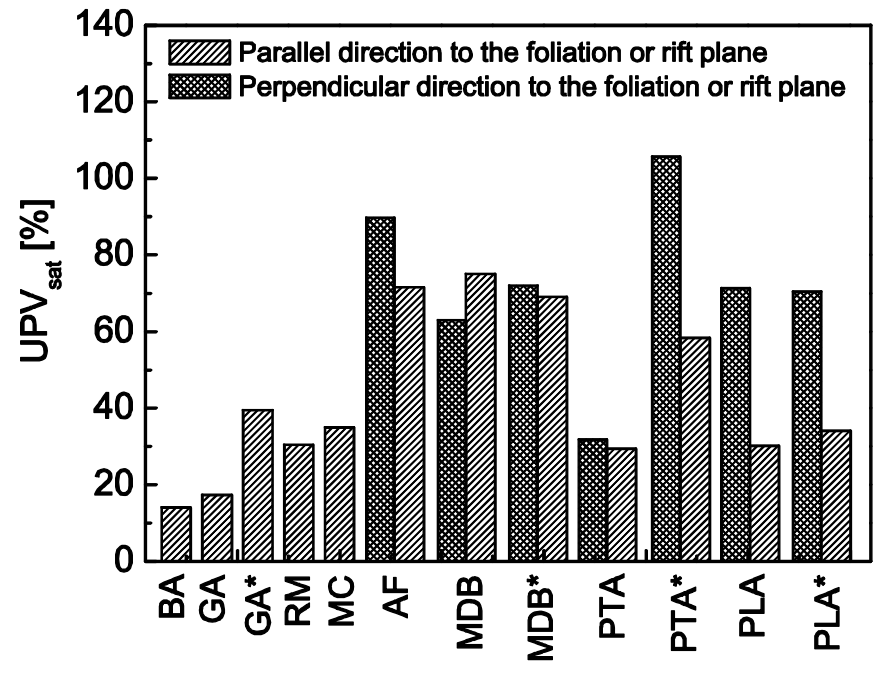

Fig. 8 .

Increase of the UPV in saturated specimens with respect to the dry specimens 


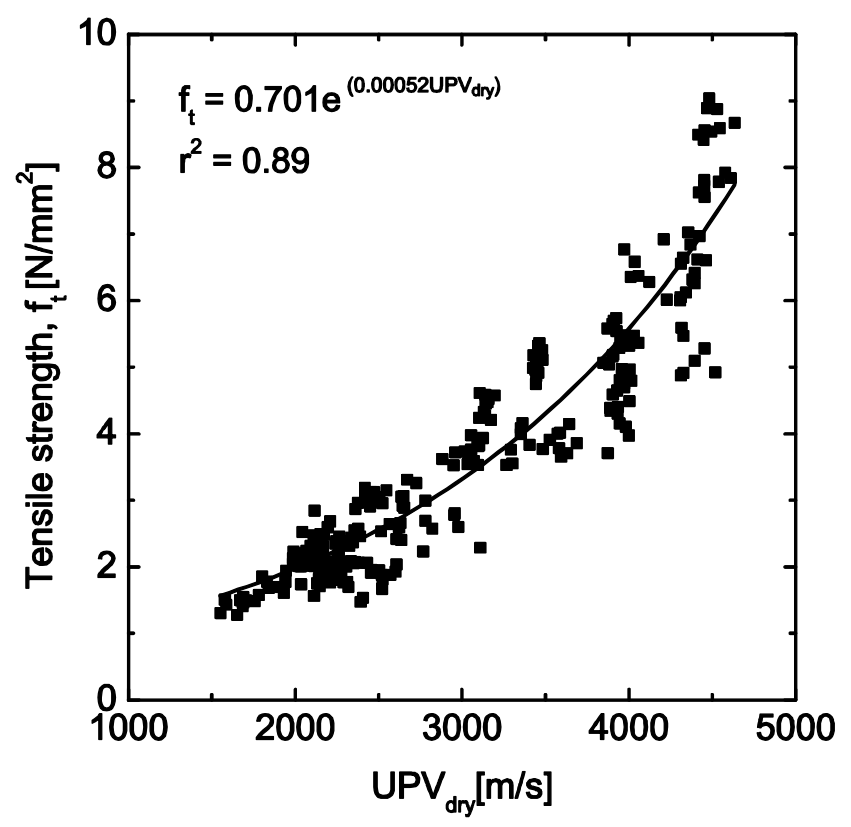

(a)

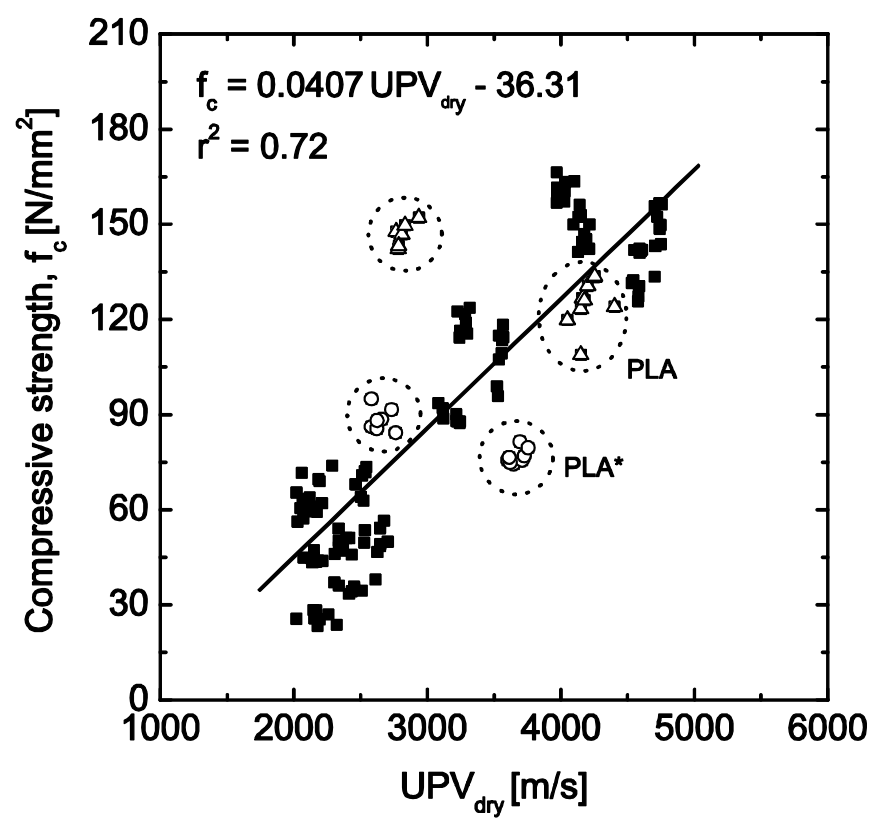

(b)

Fig. 9.

Relationship between ultrasonic pulse velocity and the granite strength; (a) $\mathrm{UPV}_{\text {dry }}$ vs. tensile strength;

(b) $\mathrm{UPV}_{\text {dry }}$ vs. compressive strength 


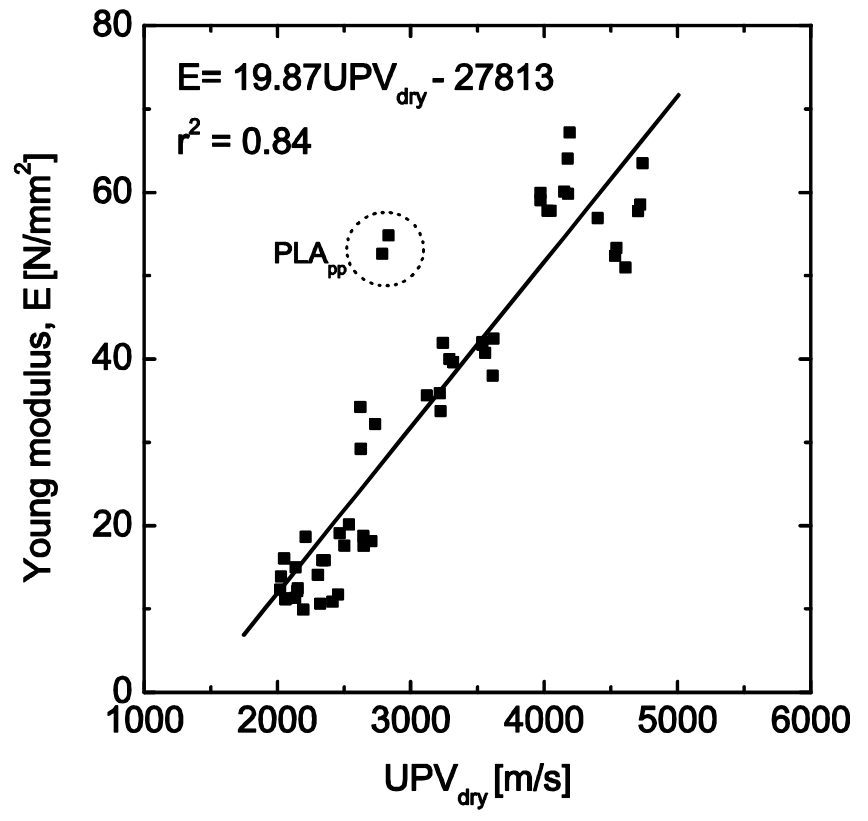

Fig. 10.

Relationship between ultrasonic pulse velocity, $\mathrm{UPV}_{\mathrm{dry}}$, and modulus of elasticity, E 


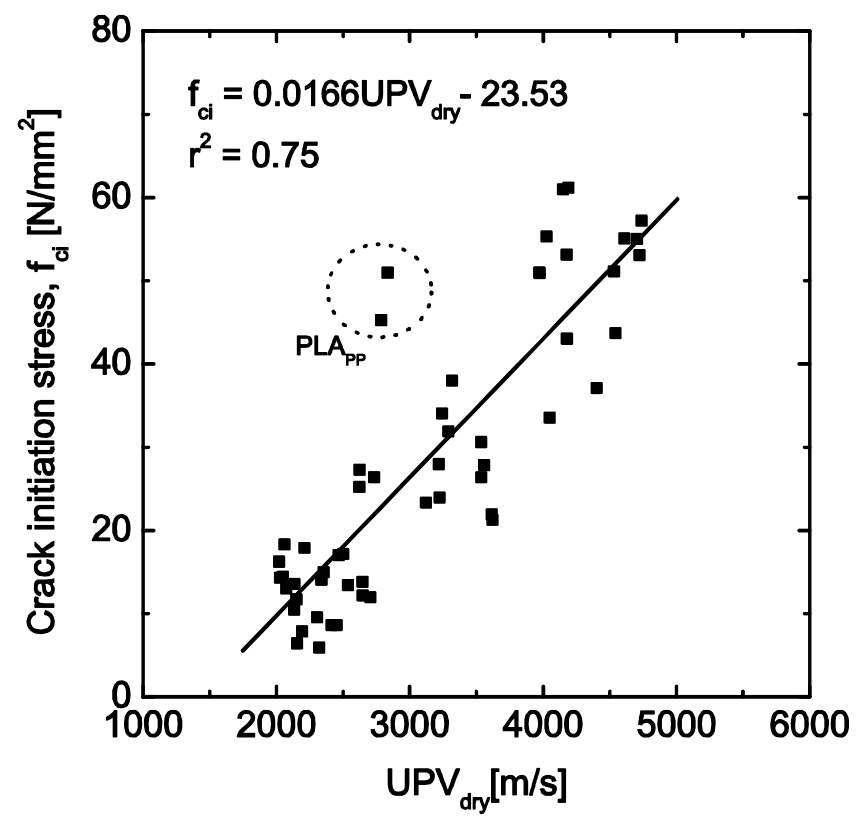

(a)

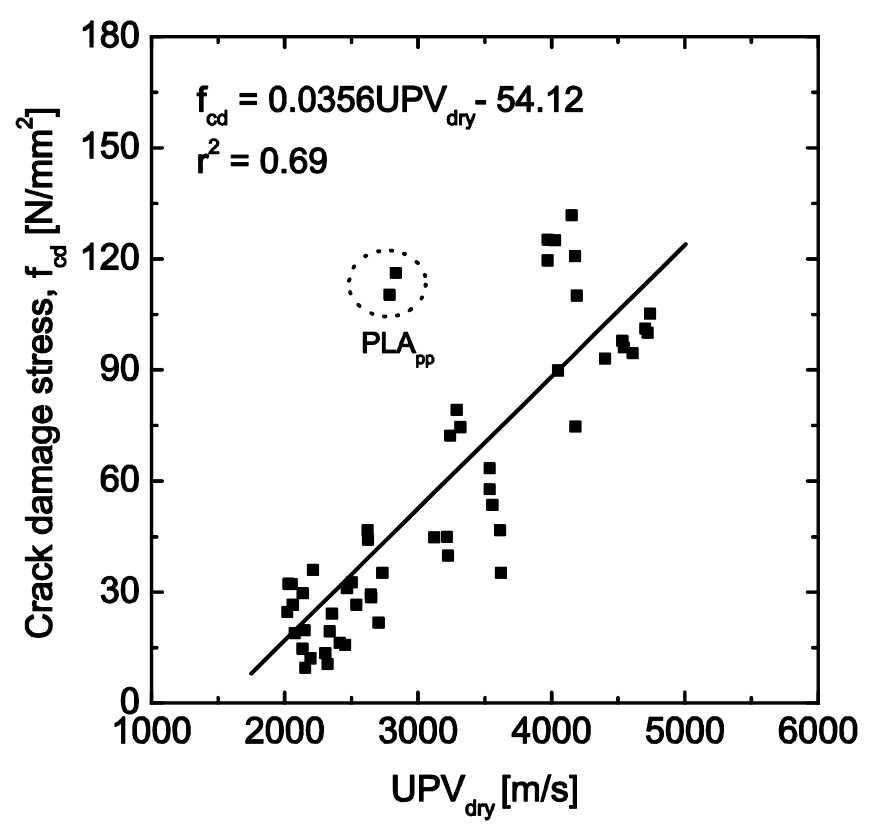

(b)

Fig. 11.

Relationship between ultrasonic pulse velocity and compressive stress levels; (a) $U_{P V} V_{\text {dry }}$ vs. crack initiation stress; (b) UPV dry vs. crack damage stress 


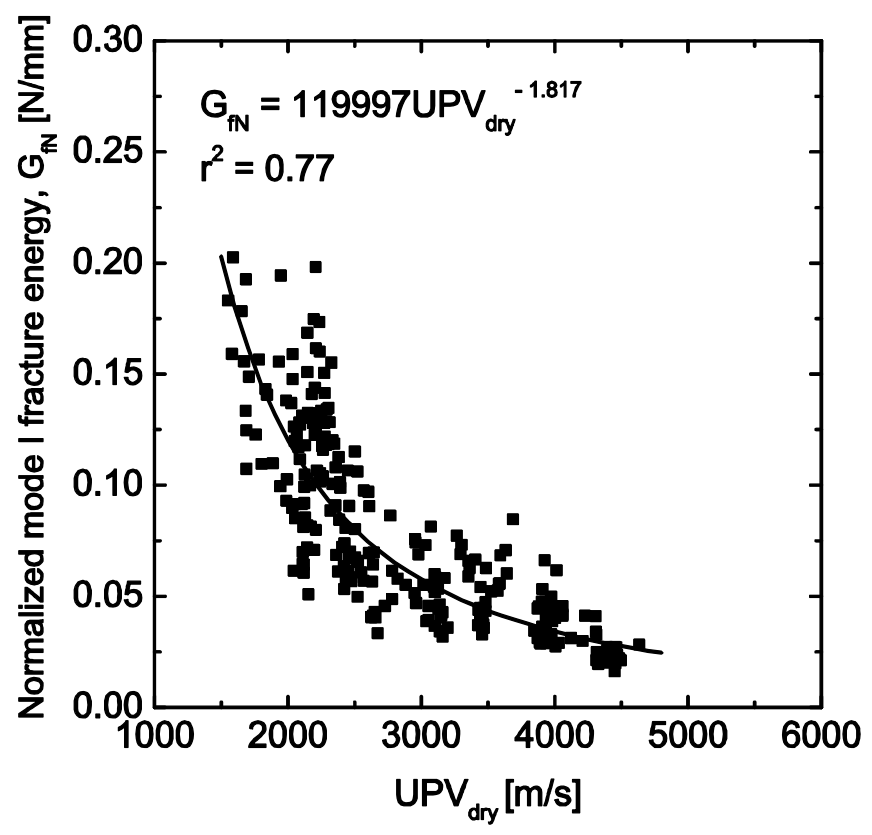

Fig. 12.

Relationship between ultrasonic pulse velocity and the tensile fracture parameter; $\mathrm{UPV}_{\mathrm{dry}}$ vs. normalized mode I fracture energy, $\mathrm{G}_{\mathrm{fN}}$ 


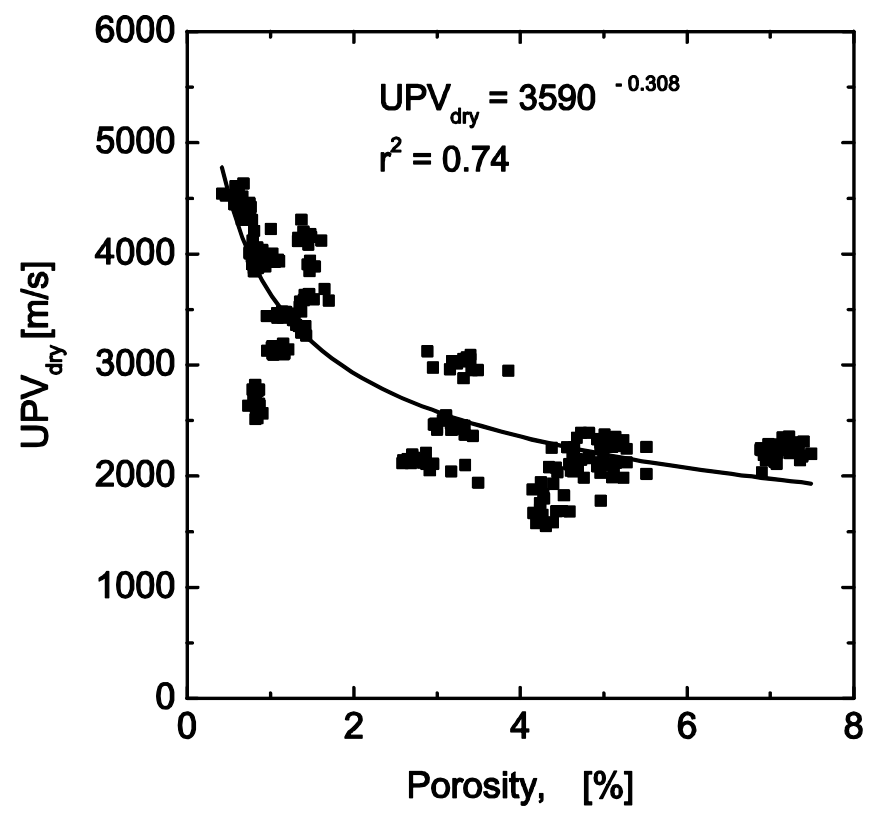

(a)

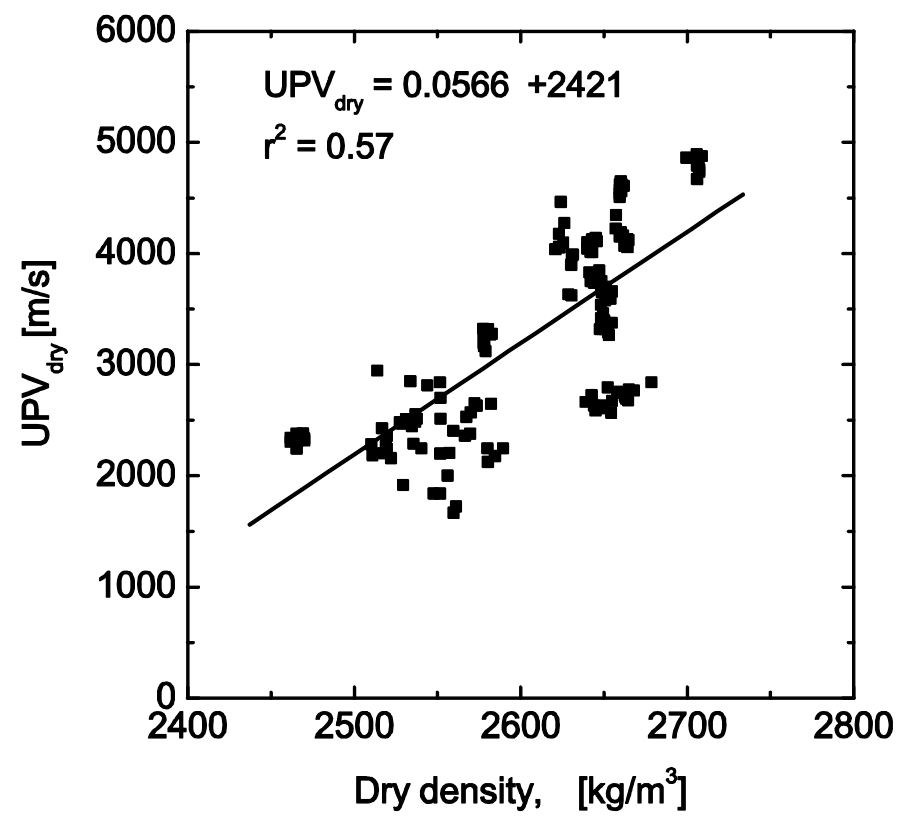

(b)

Fig. 13.

Relationship between ultrasonic pulse velocity and physical parameters; (a) porosity vs. UPV $V_{\text {dry }}$; (b) dry density vs. UPV $V_{\text {dry }}$ 